\title{
Microbial quality evaluation of awara (Soybean cheese) processed and sold at university of maiduguri campus
}

\begin{abstract}
Microbial quality evaluation of Awara sold within University of Maiduguri, Borno State was carried out. Results indicates that all the samples collected from the four cardinal point were highly contaminated, The South East (Commercial Area) which is the second cardinal point had the highest total aerobic bacteria count of 9.60x $10^{2} \mathrm{CFU} / \mathrm{g}$ and North West (Unimaid Quarters) which is the fourth cardinal point had the lowest count of $4.53 \times 10^{2} \mathrm{CFU} / \mathrm{g}$. South East had the highest coliform count of $3.87 \times 10^{2} \mathrm{CFU} / \mathrm{g}$ while North West had the lowest coliform count of $157 \times 10^{2} \mathrm{CFU} / \mathrm{g}$. Total yeast ranged from $3.33 \times 10^{2}$ in South East to $1.07 \times 10^{2} \mathrm{CFU} / \mathrm{g}$ in South West (Acada Area). Total mould was high in South East with $2.67 \times 10^{2} \mathrm{CFU} / \mathrm{g}$ while North West had the lowest mould count of $1.00 \times 10^{2} \mathrm{CFU} / \mathrm{g}$. Staphylococcus count was high in North East (Complex Area) which ranged from 3.57x $10^{2}$ to $1.57 \times 10^{2 \mathrm{CFU} / \mathrm{g}}$ in North West (Unimaid Quarters). Although all the Awara samples showed growth on various culture media with varying counts but the population was not high enough to produce effective dose. However, the need for processors of Awara to adopt strict hygiene practices cannot be overemphasized.
\end{abstract}

Keywords: microbial, quality evaluation, awara, consumption
Volume 6 Issue I - 2018

\author{
Charles Bristone,' Hauwa Abdulrahman \\ Mshelia,' Ogori FA, ${ }^{2}$ Badau MH,' Joeguluba \\ Ogori $^{3}$ \\ 'Department of Food Science and Technology, University of \\ Maiduguri, Nigeria \\ ${ }^{2}$ Department of Home Sciences, Federal University Gashua, \\ Nigeria \\ ${ }^{3}$ Department of Agricultural Education, Federal College of \\ Education Kontagora, Nigeria
}

Correspondence: Ogori FA, Department of Home Sciences, Federal University Gashua, Nigeria,

Email ogorifaraday@gmail.com

Received: December 01, 2017 | Published: January 31, 2018
Abbreviations: NE, north east; SE, south east; SW, south west; $\mathrm{NW}$, north west; CFU, colony forming unit

\section{Introduction}

Awara is an unfermented soybean product (also known as soybean curd). It is a soft- cheese -like food produced by curding fresh hot soy milk with either a salt or an acid. ${ }^{1}$. Awara also known as Tofu is an important dietary snack food throughout Asia. It is the most important and popular food product from soybean in Eastern and Southern Asian countries. It is also gaining an increasing popularity in Western countries. Awara was developed some 2000 years ago and has become the world's most popular soy food product due to its high protein. ${ }^{1}$

Soybean (Glycine max) has been proven suitable for the production of Awara. ${ }^{2}$ It is a legume of an exceptionally high protein content ranging between $38 \%$ and $42 \%$ with lysine constituting a substantial proportion. ${ }^{2}$ Soybean is considered as a good source of plant protein to man. It is also cheaper and could serve as an alternative to animal protein sources. It contains up to $40 \%$ protein compared with $1.0 \%$ to $5.6 \%$ protein content of most animal milk. ${ }^{3}$ Soybean is one of the most important legumes of the tropics. It has gained an increase in its utilization as a stable crop due to its high nutritional and excellent functional properties. It is also rich in carbohydrates $(27.1 \%)$ and oil $(20.6 \%)$ as reported by Osundahunsi et al., ${ }^{4} \&$ kolawole et al. ${ }^{5}$ Soybeans contain Omega 3 fatty acids, devoid of cholesterol and easily digestible if properly processed. It contains phytoestrogens like isoflavones, genistein that have been reported in the prevention of cancer. Isoflavones are closely related to the antioxidant flavonoids. ${ }^{6}$

In Nigeria, Awara has been regarded as a cheap source of protein that is readily available and affordable for common man as compared to animal food products. ${ }^{6}$ This product due to its nutrient and high moisture content makes it suitable to the growth of microorganism, especially if there is no good manufacturing practices and proper storage that would increase its self-life. Awara has been used as meat and cheese substitute in rural and urban areas of South West Nigeria. Local processing of soy-cheese is usually done at the home level and usually has no good processing methods.

It is important to provide current knowledge and possible future developments in food (Awara) safety. This study tends to investigate the microbiological quality of Awara sold within University of Maiduguri. Awara have been identified to have a limited shelf-life and so a potential health hazard to it consumers. Therefore, microbiological quality evaluation of Awara will be very important in order to ascertain its safety levels. Identifying different microorganism of Awara and its health implication on the consumers is imperative. This research seeks to ascertain the consequence of consuming foods been hawked within the University of Maiduguri campus.

\section{Materials and methods}

\section{Study area}

This study was conducted inside University of Maiduguri Campus, Borno State of Nigeria. Samples of Awara sold within the University of Maiduguri Campus were collected. The samples were collected from the four-cardinal point of the University of Maiduguri. Each of the three-samples collected from the cardinal point were replicated and analysed as described by Zumbes et.al. ${ }^{7}$ All chemicals and reagents were obtained from the Department of Food Science and Technology, University of Maiduguri. Description of food.

The food used is called Awara (Plate 1). It is a ready to eat (RTE) food product which is also called tofu (soybean cheese or cake). It is light brown in colour with rectangular shape and normally in medium chewable sizes. It has a cheese like taste and soft in texture with egg flavour or aromas as describe by Fasoyiro. ${ }^{8}$ 


\section{Samples and sampling}

A total of twelve (12) samples were collected from University of Maiduguri, from four cardinal points (North East, South East, South West and North West). Three (3) samples from each of the four cardinal points were collected from Awara vendors /hawkers within the university. The samples were collected aseptically in a sterile container. They were labelled and immediately transported to the laboratory for the microbial analysis as describe by Jideani and Jideani $^{9}$ (Figure 1).

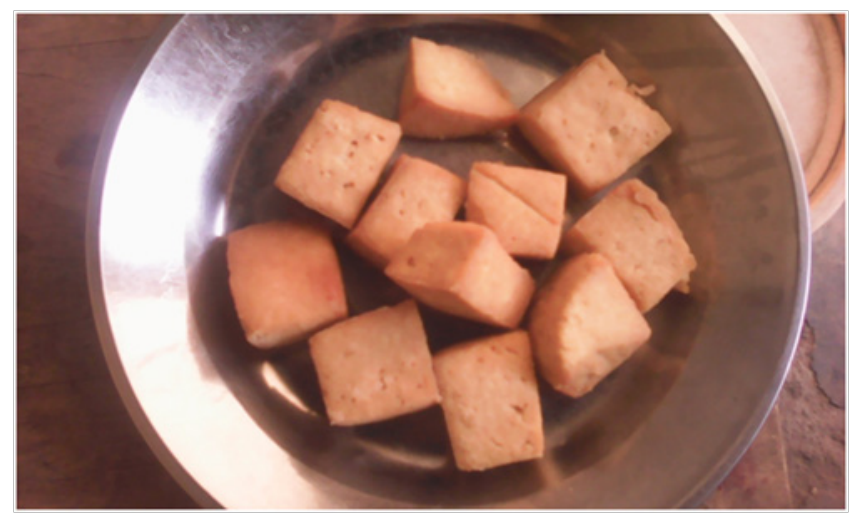

Figure I wara.

\section{Sterilization of materials}

All glass ware including conical flask, beakers, test tube, and bottles were washed thoroughly with detergents, rinsed with distilled water. They were dried and sterilized in analytical oven at temperature of $160^{\circ} \mathrm{C}$ for 1 hour. ${ }^{9}$ The media were also sterilized in autoclave at a temperature of $121^{\circ} \mathrm{C}$ for 15 minutes. All materials were sterilized before being used. ${ }^{9}$

\section{Preparation of culture media}

Nutrient agar (NA): This microbial medium was prepared by using $28 \mathrm{~g}$ of nutrient agar powder in $1000 \mathrm{ml}$ of distilled water in a clean flask. The mouth of the flask was plug with non-absorbent cotton wool and then wrapped with aluminium foil, extended up to the neck of the flask. The flask was agitated gently to mix well and was place on a bunsen burner: to boil and dissolve completely. It was sterilized by autoclaving at $121^{\circ} \mathrm{C}$ for 15 minutes and allowed to cool to $45^{\circ} \mathrm{C}$. It was aseptically dispensed into pretidish. These media were used for the total bacterial aerobic plate count. ${ }^{10}$

Peptone water (PW): Peptone water was prepared by dissolving $15 \mathrm{~g}$ of the powder in 1litre of distilled water. It was mixed well and distributed into final bottle and sterilize by autoclaving for 15 minutes at $121^{\circ} \mathrm{C}$. Peptone water was use as growth medium. ${ }^{10}$

MacConkey agar (MA): MacConkey agar, bile salt, peptone and salt were dissolved in distilled water and agar-agar was added. It was autoclaved at $121^{\circ} \mathrm{C}$ for 15 minutes. The final $\mathrm{pH}$ was adjusted to 7.5. Lactose was also added and mixed followed by neutral red in sufficient amount to give a redish-brown colour. It was dispensed in bottles and autoclaved at $121^{\circ} \mathrm{C}$ for 10 minutes, then allowed to cool to $45^{\circ} \mathrm{C}$ before pouring into plates. This was done to prevent scum from appearing on the surface of the medium. The final mixture was reddish-brown in colour. This was done to determine Coliform count as described by Cheesbrough. ${ }^{10}$

Corn meal agar (GMA): This medium was used to determine yeast count. Corn meal agar was prepared by dissolving $17 \mathrm{~g}$ of the powder in $1000 \mathrm{ml}$ of distilled water. It was heated gently to dissolve completely. One percent polysorbate was added and sterilized in autoclave at $12 \mathrm{I}^{\circ} \mathrm{C}$ for 15 minutes. It was allowed to cool at room temperature before pouring into Petri dishes containing the samples as describe by Cheesbrough. ${ }^{10}$

Potato dextrose agar (PDA): The medium was prepared by weighing $39 \mathrm{~g}$ of potato dextrose agar powder in distilled water. It was heated to boil completely, and then sterilized by autoclaving at $121^{\circ} \mathrm{C}$ for 15 minutes. This was used to determine mould count in the samples. ${ }^{10}$

Mannitol salt agar (MSA): The medium was used for isolation and enumeration of Staphylococcus aureus. For this preparation, 108g of MSA powder (Lab. M. Limited) was weighed and dissolved in $1000 \mathrm{ml}$ of distilled water. It was allowed to stay for 10minutes. After that, it was swirled, homogenised and sterilized by autoclaving at $121^{\circ} \mathrm{C}$ for 15 minutes. Then, it was allowed to cool before being poured in to petri dishes. ${ }^{10}$

\section{Serial dilution}

Serial dilution was prepared by introducing 1 gram of Awara with a sterile blade. A plastic rack was arranged with sterile test tubes containing $9 \mathrm{ml}$ of distilled water. A tenfold serial dilution was carried out by homogenizing 1 gram of the sample into the test tube and was labelled as $10-1$. It was mixed thoroughly and $1 \mathrm{ml}$ was taken again from the 10-1 dilution tube and transferred into the next test tube (labelled 10-2). Each test tube was shaken vigorously before each transfer as describe by Jideani. ${ }^{9}$

\section{Plating of culture and incubation}

Pour plate method was used for plating the samples. One millilitre from the dilution 10-2 was taken using sterile pipette and then it was introduced into sterile petri dish, these were done in triplicate for each one of the 12 samples of Awara. The prepared media were poured into the Petri dishes containing $1 \mathrm{ml}$ of diluted culture. The plates were swirled to mix properly. All plates were allowed to solidify on a bench before incubation. ${ }^{9}$. The plates were incubated at $35^{\circ} \mathrm{C}$ for 24 hours .Similarly Yeast and mould were incubated at room temperature for 7 days and were observed daily to allow them grow for easy identification. ${ }^{11}$

\section{Viable cell count}

Colony counting machine was used for counting the total bacterial aerobic plate count of the plates. ${ }^{11}$

\section{Gram staining technique}

Gram staining reaction has the wide application that is capable of distinguishing virtually all gram positive and gram-negative bacteria. Smear of each isolate was made on the slide and heat fixed. Primary stain (crystal violet) was applied for 45 second and washed with gentle running water. Lugol's iodine was added for 45 seconds and was decolorized with acetone - alcohol and washed with clean water. The slides were counter stained with $30 \%$ safranin for 30 second and washed. It was then air dried and examined at under oil immersion lens of the microscope used. ${ }^{10}$

\section{Motility test}

Motility was performed using agar with concentration of $0.2-0.5 \%$ $(\mathrm{w} / \mathrm{v})$ was inoculated with the test organism. A stab of each inoculum was made at the centre of each tube. The tube was incubated at $35^{\circ} \mathrm{C}$ for 24hours. The temperature was reduced for Pseudomonas. A 
diffused growth at the place of inoculation is considered as positive and restricted growth is considered as negative. ${ }^{10}$

\section{Catalase test}

Catalase test used to determine whether or not a microorganism produces catalase enzyme. A loop full of the culture was placed on a clean grease free slide. The culture was emulsify with a loop full of freshly prepared $3 \%$ hydrogen peroxide $\left(\mathrm{H}_{2} \mathrm{O}_{2}\right)$ on the slide and the reaction was observe immediately for catalase positive or negative organism. ${ }^{10}$

\section{Coagulase test}

Coagulase test is particularly employed to differentiate pathogenic Staphylococcus aureus from the non-pathogenic species. Coagulase test was done by slide method using culture from solid media. A clean grease free slide was divided into two using a grease pencil. A drop of normal saline $(0.85 \%)$ was placed on each of the portions and 18 hour culture of the tests organism was emulsified in little quantity on each of the drops of normal saline until a uniform suspension was obtained. A drop of rabbit plasma was added to one of the suspensions and stirred for about 5 seconds for the presence of Coagulase positive or negative organisms. ${ }^{10}$

\section{Oxidase test}

Oxidase test was carried out using petri dish method. A drop of $1 \%$ aqueous solution of the reagent was placed on the portion of the culture plate containing the test organism. The reaction was observed between 10 seconds. ${ }^{10}$

\section{Urease test}

Urease test was carried out to determine if a microorganism produces the enzyme urease. Urease broth was prepared according to direction from the manufacturers and $5 \mathrm{ml}$ potion was dispensed into clean test tubes to obtain a slope of I inch built. It was sterilized at $121^{\circ} \mathrm{C}$ for 15 minutes before the test tube was kept in a slanting position to set. The slope surface was inoculated by streaking with a loop full of the peptone water broth culture. It was incubated at $35^{\circ} \mathrm{C}$ for 24 hours before the reaction was observed. Pink colour of the media indicated Urease positive. ${ }^{10}$

\section{Indole test}

Peptone water was prepared by adding $10 \mathrm{~g}$ tryptone to $100 \mathrm{ml}$ distilled water. Exactly $0.5 \mathrm{~g}$ of sodium was added to the solution and the $\mathrm{pH}$ was adjusted to final $\mathrm{pH}$ of 7.2. Then, $5 \mathrm{ml}$ was dispensed into sterile test tubes and were covered loosely and autoclaved at $121^{\circ} \mathrm{C}$. It was allowed to cool to $30^{\circ} \mathrm{C}$ and was inoculated and incubated at $35^{\circ} \mathrm{C}$ for 48 hours. After that, $0.5 \mathrm{ml}$ of kovac's reagent was added and was gently shaken. It was allowed to stand for 10minutes. The reaction was observed for red positive colour. ${ }^{10}$

\section{Voges-proskauer test}

Glucose-phosphate was prepared and sterilized as the growth

Table I Microbiological Count (CFU/g) of Awara obtained from the Four Cardinal Points of University of Maiduguri

\begin{tabular}{llllll}
\hline Sample & TBAC & CC & YC & SC & MU \\
\hline North east & & & & \\
\hline Al & $7.73 \times 10^{2}$ & $3.20 \times 10^{2}$ & $1.20 \times 10^{2}$ & $2.00 \times 10^{2}$ & $1.07 \times 10^{2}$ \\
A2 & $9.07 \times 10^{2}$ & $2.27 \times 10^{2}$ & $1.10 \times 10^{2}$ & $3.33 \times 10^{2}$ & $1.10 \times 10^{2}$ \\
A3 & $6.27 \times 10^{2}$ & $2.07 \times 10^{2}$ & $2.67 \times 10^{2}$ & $3.57 \times 10^{2}$ & $1.20 \times 10^{2}$ \\
\hline
\end{tabular}




\begin{tabular}{|c|c|c|c|c|c|}
\hline Sample & TBAC & CC & YC & SC & MU \\
\hline \multicolumn{6}{|c|}{ South east } \\
\hline $\mathrm{BI}$ & $7.40 \times 10^{2}$ & $3.83 \times 10^{2}$ & $2.00 \times 10^{2}$ & $2.33 \times 10^{2}$ & $2.67 \times 10^{2}$ \\
\hline B2 & $7.93 \times 10^{2}$ & $2.23 \times 10^{2}$ & $3.33 \times 10^{2}$ & $2.20 \times 10^{2}$ & $2.33 \times 10^{2}$ \\
\hline B3 & $9.60 \times 10^{2}$ & $2.40 \times 10^{2}$ & $1 .{ }^{2} 0 \times 10^{2}$ & $1.73 \times 10^{2}$ & $1.23 \times 10^{2}$ \\
\hline \multicolumn{6}{|c|}{ South west } \\
\hline $\mathrm{Cl}$ & $5.60 \times 10^{2}$ & $1.77 \times 10^{2}$ & $1.07 \times 10^{2}$ & $1.80 \times 10^{2}$ & $1.07 \times 10^{2}$ \\
\hline $\mathrm{C} 2$ & $6.67 \times 10^{2}$ & $3.40 \times 10^{2}$ & $2.33 \times 10^{2}$ & $3.13 \times 10^{2}$ & $1.20 \times 10^{2}$ \\
\hline $\mathrm{C} 3$ & $5.87 \times 10^{2}$ & $2.40 \times 10^{2}$ & $2.33 \times 10^{2}$ & $2.40 \times 10^{2}$ & $1.33 \times 10^{2}$ \\
\hline \multicolumn{6}{|c|}{ North west } \\
\hline DI & $5.00 \times 10^{2}$ & $3.20 \times 10^{2}$ & $1.07 \times 10^{2}$ & $1.57 \times 10^{2}$ & Nil \\
\hline D2 & $4.97 \times 10^{2}$ & $1.67 \times 10^{2}$ & $1.27 \times 10^{2}$ & $2.00 \times 10^{2}$ & $1.00 \times 10^{2}$ \\
\hline D3 & $4.53 \times 10^{2}$ & $1.57 \times 10^{2}$ & $2.33 \times 10^{2}$ & $2.17 \times 10^{2}$ & $1.77 \times 10^{2}$ \\
\hline
\end{tabular}

Key:TBC, total bacteria aerobic count; CC, coliform count; YC, yeast count; SC, staphylococcal count; MC, mould count

AI to D3 are replications from the respective cardinal points

From the result obtained in these analyses, South East (Commercial Area) had the highest bacterial count. Since the processing of these foods normally involve a form of heat treatment, it is obvious that considerable number of Bacteria associated with raw materials would have been killed. The reason for high microbial load might be attributed to presence of heat resistance and post handling contamination. ${ }^{7}$ This agrees with the fact that immense microbial contamination of food is linked to poor post processing handling practices. Therefore, the microbial load on the foods is an index of poor sanitary conditions during preparation storage and personal hygiene of the food by handlers. ${ }^{7}$

The presence of coliforms from South East (Commercial Area) is high compared to other location and can be as a result of unhygienic practices related to faecal or sewage contaminations through the use of contaminated water, equipment and hand carriage, while North West (Staff Quarters Area) had the lowest coliform count and these could be as a result of different handling practices, water source and environment. ${ }^{12}$

Yeast count was indicated to be high in South east (Commercial

Table 2 Morphological and biochemical characteristics of the microorganisms isolated from Awara from four cardinal points of University of Maiduguri campus

\begin{tabular}{|c|c|c|c|c|c|c|c|c|c|c|c|}
\hline \multirow{2}{*}{$\begin{array}{l}\text { Morphological } \\
\text { Characteristics }\end{array}$} & \multicolumn{10}{|c|}{ Biochemical Characteristics } & \multirow[b]{2}{*}{ Microorganism } \\
\hline & $\begin{array}{l}\text { Gram } \\
\text { reaction }\end{array}$ & Motility & Coagulase & Catalase & Oxidase & Urease & Indole & $\begin{array}{l}\text { Voges- } \\
\text { Proskauer }\end{array}$ & $\begin{array}{l}\text { Citrate } \\
\text { Utilization }\end{array}$ & $\begin{array}{l}\text { Methyl } \\
\text { red }\end{array}$ & \\
\hline $\begin{array}{l}\text { Smooth cream, } \\
\text { opaque colonies } \\
\text { with entire edge }\end{array}$ & + Cocci & - & + & + & + & - & - & - & - & + & $\begin{array}{l}\text { Staphylococcus } \\
\text { aureus }\end{array}$ \\
\hline $\begin{array}{l}\text { Smooth, pink, } \\
\text { circular colonies } \\
\text { that ferment } \\
\text { Lactose }\end{array}$ & $-\operatorname{Rod}$ & + & - & - & + & + & + & - & - & - & Escherichia coli \\
\hline $\begin{array}{l}\text { Large flat, spread } \\
\text { colonies with } \\
\text { smell }\end{array}$ & - Rod & - & + & + & + & - & - & - & + & - & Pseudomonas \\
\hline $\begin{array}{l}\text { Large grey white } \\
\text { mucord colonies }\end{array}$ & - Rod & + & - & - & + & - & - & + & + & - & Salmonella \\
\hline Pale colour non & - Rod & - & + & + & - & - & - & - & - & + & Shigella \\
\hline
\end{tabular}

Citation: Bristone C, Mshelia HA, Ogori FA, et al. Microbial quality evaluation of awara (Soybean cheese) processed and sold at university of maiduguri campus.J Bacteriol Mycol Open Access. 2018;6(I):30-34. DOI: I0.15406/jbmoa.20I8.06.00I72
Area) and low in South west (Acada area) which is due to direct exposure to air. Sule et al., ${ }^{13}$ reported that, dusty, unhygienic environment coupled with poor handling by vendors are factors contributing to the high,, microbial lead. However, mould count was indicated to be high in South East and low in North West. This may be attributed to humidify air concentration.

Staphylococcus is associated specifically, with the hands and nasal cavity. The deposition of this microorganism in Awara can occur if good sanitary practices are not followed by the food handlers. Staphylococcus aureus is a pathogenic microorganism which could result in the transmission of diseases. ${ }^{13}$

\section{Morphological and biochemical characteristics of microorganisms isolated from awara}

Table 2 shows the morphological and biochemical characteristics of microorganisms isolated from Awara (Soybean Cheese). From the result obtained Staphylococcus aureus is predominantly found. Hence the presence of these organisms indicates contamination from food handlers. S. aureus is a pathogenic and it produces toxin, which causes staphylococcal food poisoning. ${ }^{14}$ 
The presence of E. coli is an indicator of faecal contamination which could be attributed to the method used in the preparation, unhygienic activities of the handlers. Specie of pseudomonas spp organisms are widely distributed in water, soil and sewage. The presence of Salmonella and Shigella in Awara is an indicator of postprocessing contamination which could cause typhoid fever and other food poisoning. ${ }^{13-17}$

Table 3 shows the percentage occurrence of microorganism isolate from Awara. The occurrence of Staphylococcus aureus in
Awara was $37.5 \%$, Salmonella spp $37.5 \%$, E. coli $50 \%$, Shigella $3.7 \%$, Pseudomonas spp $25 \%$, Candida albicas $12.5 \%$, Saccharomyce cerevisae $37.5 \%$, Rhizopus oryza $12.5 \%$. The occurrence of E. coli, shigella. In Awara was an indication of faecal and environmental contamination and a signal for the presence of other enteric pathogenic. ${ }^{13}$ The occurrence of fungi in Awara may be due to contamination from air, dust, packaging material, poor hygiene and sanitation of the processing environment and thus producing mycotoxins which can cause mycotoxicosis in humans Sule et al. ${ }^{13}$

Table 3 The percentage frequency of occurrence of microorganisms isolated from Awara from four cardinal points of University of Maiduguri

\begin{tabular}{|c|c|c|c|c|c|}
\hline \multirow{2}{*}{ Microorganism } & \multicolumn{4}{|c|}{ University Of maiduguri four cardinal points } & \multirow{2}{*}{$\%$ Occurrence } \\
\hline & North East & South East & South West & North West & \\
\hline Staphylococcus aureus & + & + & + & - & $37.50 \%$ \\
\hline Salmonella sp. & + & + & + & - & $37.50 \%$ \\
\hline Escherichia coli & + & + & + & + & $50 \%$ \\
\hline Shigella & + & - & + & + & $37.50 \%$ \\
\hline Pseudomonas sp. & + & + & - & - & $25 \%$ \\
\hline Candida albicas & + & - & - & - & $12.50 \%$ \\
\hline Saccharomyces cerevisae & + & + & + & - & $37.50 \%$ \\
\hline Rhizopus oryza & - & + & - & - & $12.50 \%$ \\
\hline
\end{tabular}

\section{Conclusion}

From the result obtained in this study, most of the Awara (Soybean cheese) samples obtained from the four cardinal points are not fit for consumption since they have been contaminated by both pathogenic and spoilage microorganisms. It is important to keep cheese fit for consumption by taking adequate measures to prevent contamination during and after production of Awara.

\section{Acknowledgements}

None.

\section{Conflict of interest}

The author declares no conflict of interest.

\section{References}

1. Egbo NN. Nigeria: M.Sc. Thesis in the Department of Microbiology, University of Port Harcourt; 2012. p. 1-97.

2. Egbo AO, Seidu KT. Microbiological evaluation of suya (diel smoked meat) sold in Ado and Akure, South west: Nigeria. European Journal of Experimental biolog. 2012;1(4):1-5.

3. Farinde EO, Obatolu VA, Fasoyiro SB, et al. Use of Alternative raw materials for Yoghourt production. Afri J Biotechnol. 2008;7(33):3339 -3345 .

4. Osundahunsi OF, Amosu D, Ifesan BOT. Quality evaluation and acceptability of Soy-yoghourt with different colors and fruit flavours. American Journal of Food; 2007

5. Falade KO, Ogundele OM, Ogunshe AO, et al. physico-chemical sensory and microbiological characteristics of plant yoghurt from bambara groundnut and soybeans. J Food Sci Technol. 2015;52(9):5858-5865.

6. Beatrice, Olawumi T, Oguntoyinbo, et al. production of tofu from blends of soybean and sesame seed. African Journal of Food Science. 2012;14(6):386-391.
7. Zumbes JH, Dabo AD, Dakul DA, et al. Entero pathogenic Bacterial contamination of some ready to eat foods sold in Jos metropolis Nigeria. 456 Indian Journals of Applied Research. 2014;4(7):456-458.

8. Fasoyiro SB. Assessment of hazards in local soy-cheese processing: implication on health and environment in Oyo State, Nigeria. WIT transaction on Ecology and the environment. 2011;152(8):37-44.

9. Jideani S. Cost effectiveness of a targeted disinfection program in household kitchens to prevent food -borne illness in the United states, Canada and the United Kingdom. Journal of food protection. 2003;66(11):2103-2115.

10. Cheesbrough M. District laboratory practice: In tropical countries. Part 2, 2nd ed. USA: Cambridge University press; 2006.

11. Mbajiuka CS, Obeagu EI, Ifediora AO, et al. Isolation and identification of microorganisms involved in the spoilage of soymilk. IOSR Journal of Pharmacy and Biological Sciences volume. 2014;9(5):29-36.

12. Bukar AI, Uba A, Oyeyi TI. Occurrence of some entero pathogenic bacteria in some minimally and fully processed ready to eat foods in Kano metropolis, Nigeria. African Journal of Food Science. 2009;4(2):032036 .

13. Agbabiaka TO, Oyeyidu G, Salisu BK, et al. Microbiological Assessment of some locally retailed cheeses within Ilorin Metropolis. Nigerian Journal of Microbiology. 2015;27(1):2680-2687.

14. Daniyan SY, Abalaka, Momoh ME, et al. Microbiological and physiochemical assessment of street vended soybean cheese sold in Minna. Nigeria International Journal of Biomedical and Advance Research. 2011:2(1).

15. WWW.cfs.gov.uk/English/food-leg/files/food-leg-MicrobiologicalGuidelines-for-Food-e.pdf

16. Fawoyo PT. Microbiological assessment of Air contamination of vended foods sold in the main market in lokoja, Kogi State, Nigeria. Research journal of Biological Sciences. 2012;7(9-12):355-360.

17. Ganiyu O, Ekperigin MM. Effects of types of Coagulant on the nutritive value and in vitro multienzyme protein digestibility oftofii. J Food Technology. 2007;3:182-187. 